\title{
Practising everyday climate cultures: understanding the cultural politics of climate change
}

\author{
Michael K. Goodman ${ }^{1} \cdot$ Julie Doyle ${ }^{2} \cdot$ Nathan Farrell $^{3}$ \\ Published online: 14 September 2020 \\ (C) Springer Nature B.V. 2020
}

As we write this editorial introduction, the UK is slowly emerging from its period of selfimposed lockdown restrictions due to the COVID-19 pandemic and facing the virus's lasting impacts upon society at every scale imaginable. Felt acutely in the upending of the everyday practices that define our daily routines and engagements with others, there have been monumental, far-reaching changes to the many everyday actions we, in the Minority World, take for granted. These have included a complete halt for many people of getting in the car for work or on a plane to go on holiday, to immense disruptions to the ways we do our jobs, acquire food and engage in the social relations that allow us to be family members, citizens, friends and neighbours. The pandemic shined a harsh light on these practices - for example, who can continue to work from home and who cannot, who can access and afford food delivery and who cannot - and the very real race, class and gender inequalities embedded in the ability and ways these daily routines are performed.

Significantly, the various levels of lockdown across the world have had considerable impacts on global carbon emissions, from estimations of a $17 \%$ reduction of daily emissions to a peak daily average emissions reduction of 26\% (Le Quéré et al. 2020; see also CarbonBrief 2020). Brought on by the rapid slowdown to the previously unthinkable wholesale shut-down of economies, industrial activity and transport in many parts of the world, emissions are now beginning to rise as countries open and economies re-start producing and consuming to their previous levels (NOAA 2020). The contributions in this issue of Climatic

This article is part of the Special Issue on "Everyday Climate Cultures: Understanding the cultural politics of climate change" edited by Goodman, Doyle and Farrell

Michael K. Goodman

m.k.goodman@reading.ac.uk

1 Department of Geography and Environmental Science, University of Reading, Reading, UK

2 School of Media, Centre for Spatial, Environmental and Cultural Politics, University of Brighton, Brighton, UK

3 Centre for the Study of Journalism, Culture and Community, University of Bournemouth, Poole, UK 
Change focus upon a critical lesson foregrounded by the pandemic: Our everyday livelihood and lifestyle practices have direct and recursive implications for climatic health and the ecological viability of the planet. The prospect of getting back to 'normal' everyday consumption routines and practices holds frightening possibilities for our collective futures and the rapid closing of the windows of opportunity to reconfigure everyday life in more sustainable registers suggests that the need to act is increasingly urgent. ${ }^{1}$

Before the pandemic brought the implications of the ecological impacts of everyday practices into such sharp relief, global institutions such as the IPCC pointed to the necessity of reducing high consumption lifestyles and turning instead to more sustainable consumption, all supported by positive environmental knowledge (IPCC 2014). As the IPCC argues, sustainable consumption must be 'viewed in the broader context of lifestyles and everyday life' (308). Moreover, the UN's Sustainable Development Goals (SDGs) are steeped in improving global livelihoods - especially now in light of the impacts of COVID-19 - at the scale of the everyday, from ending hunger and providing access to healthcare, medicine and education to delivering clean water, sanitation, green energy and supporting biodiversity on land and in the oceans (UN 2020b). Indeed, how can the 13th SDG of taking 'urgent action to combat climate change and its impacts' not be intimately and directly implicated in the everyday food, clothing, heating, healthcare and transport needs, abilities, choices and desires of a global population? The IPCC and the UN — both pre- and post-COVID — are in the midst of the crucial consideration of the complexities and complications of everyday life, what a lifestyle might entail, and how these might be better connected to the everyday cultures and practices of sustainability, sustainable consumption and low-carbon living. ${ }^{2}$ In addition, both of these institutions have begun to recognise the importance of considering the inescapable role of media and communication in the mediation, adoption — or indeed, rejection — of more sustainable everyday cultures and practices designed to mitigate the effects of a warming planet.

Conceptualised through the multidimensional notion of the practices of everyday climate cultures, the papers in this Special Issue address these vital concerns by exploring how our everyday practices, cultural politics and communication are implicated in both the causes and mitigation of climate change and adaptations to it. As a starting point, the authors utilise explicitly interdisciplinary social science and humanities approaches to explore how societies and individuals engage with and confront climate change through the ordinary efforts of making and practicing everyday lifestyles: from the products we buy and the foods we eat to the media and technologies we engage with. Operationalising concepts and theoretical lenses from across sociology, social psychology, cultural geography and media, communication and cultural studies, the research presented offers novel and far-reaching analyses of the relationships amongst the symbolic cultures, material practices and power relations that govern everyday sustainability - including individual and collective identities and subjectivities - in the so-called Anthropocene. In particular, drawing on sociological and geographical research on the everyday (de Certeau 1974; Hall 2019; Lefebvre 2014; Sullivan 2020) and the practices

\footnotetext{
${ }^{1}$ The UN's 'recover better' (UN 2020a) statement of attaching climate mitigation to COVID-19 recovery plans and the desire of much of the UK public to 'build back better' through support for a more climate-friendly, green economy (Vaughan 2020) has yet to be fully materialized in policy and has seemingly lost traction in efforts to fast-track the opening up of global economies.

${ }^{2}$ For example, the UN has teamed up with Futerra and other environment and development consultancy groups to develop the 'good life goals' as an accessible entry point for the public to engage with the SDGs at the level of the everyday. See https://www.goodlifegoals.org/ for their strategy and approach.
} 
of 'everyday sustainabilities' (e.g. Evans 2018, 2020; Hobson 2013; Shove 2010), the papers in this Special Issue investigate the everyday as a site of intersecting cultural values, norms, politics and practices which shape how individuals and communities engage with climate change. Developed through rich empirical detail and innovative conceptualisations, they explore how everyday climate cultures are mediated, shaped, governed and contested through wider social, economic and political systems which both enable and constrain the development of more sustainable climate practices. As such, the question of how everyday climate practices can lead to - or limit_-broader systemic changes required for the mitigation of climate change is a key concern of the Issue's papers.

Importantly, the research presented here also develops distinctive, complex understandings of the connections of culture and everyday practice to climate change media and communications (see also Evans 2019). Indeed, whilst climate scholars and practitioners have explored climate communications (e.g. Boykoff 2011; Doyle 2011; Moser 2016) and how climate change is made culturally meaningful (e.g. Doyle et al. 2017; Hulme 2016; Norgaard 2011), how climate cultures are practiced at the level of everyday communications has received far less critical attention. As such, much like Munshi et al.'s (2020) exhortations that culture should be situated at the forefront of the understanding of public engagement on climate change, the papers here approach climate change as a unique, yet fundamentally contextualised cultural issue that is practiced and contested by individuals and communities at the scale of everyday communications through the ordinary routines, performances, traditions and habits of media consumption and engagement. In doing so, this Special Issue brings together questions and research on climate culture, media and politics to explore their interconnected convergence through the lenses of lifestyles, livelihoods and everyday life. And, although all of the work presented here was researched and written-up pre-COVID, the contributions set the stage for how the current and future practices of everyday climate cultures might be reimagined, re-thought, communicated and envisioned anew in the building of a greener and more socially and environmentally just post-COVID world.

In order to explore the above concerns, the eight papers in this Special Issue critically interrogate and explore the practices of everyday climate cultures through four interwoven and related themes: (1) media and communication, (2) culture as a contested site of climate knowledge and practice, (3) users and socio-material practices and (4) the role of corporations in everyday carbon economies. In addition, in the spirit of further developing the broad interdisciplinarity core to our collective vision for this Issue, we invited two cultural theorists - Toby Miller and Alex Lockwood - to reflect critically on the content of the Issue's papers and their overarching themes. Both pieces are distinctive in their assessment of the papers' arguments as Miller and Lockwood, who have done far-reaching research and commentary on climate cultures and practices in their own right, had complete creative licence in producing their commentaries. Both of these important pieces push the boundaries of the research presented here in innovative intellectual, stylistic and political directions.

The first contribution by Miller (2020) entitled 'Inviting Critical Political Economy to the table' is a concluding commentary in which he reflects and builds on the above themes and the papers' arguments at the same time offering up his own, unique take on the practices of everyday climate cultures. For Miller, the theoretical lens of 'critical political economy' is required to understand and analyse the practices of everyday climate cultures and establish critique and critical theory as front and centre to any ecological and social politics surrounding climate change and its everyday practices. His piece - much like his other writing and research — challenges us to consider not just the political and 'real-world' material weaknesses 
of working to mitigate climate change at the scale of everyday practices but how this invariably has been captured by corporate and political capital in ways that work to blunt the kinds of structural and transformational changes sorely needed to confront the climate crisis.

The second contribution by Lockwood (2020) is a piece of imaginative speculative fiction entitled 'An Address to the Corporales of the Republic of Sunlight'. It both engages in detail with the material in the Issues' papers and also builds into a science fiction, first-person narrative about our ecological and political futures. This contribution is centred on performing new and 'unsettling' narrative styles to facilitate communication strategies outside of academic parlance and the conservative, 'safe' landscapes of academic publishing. Lockwood's piece appears on his Academia.edu webpage ${ }^{3}$, and we see his pioneering tactics of 'writing through' and about problematic climate cultures in this fictional narrative approach as an important marker in carving out innovative, confrontational story-telling spaces from which to challenge the climate crisis.

The first two papers of the Issue focus on the role of media and communication in the shaping of climate knowledges and practices at the level of the everyday, calling attention to the power of framing and advocacy in the communication and contestation of climate change. Taking a longitudinal approach to the study of climate imagery, Saffron O’Neill (2020) explores how UK and US newspapers visually depict climate change during the period 2001-2009, an important decade for the expansion and consolidation of climate change science, activism and engagement. Utilising framing analysis, O'Neill explores the use of a distancing and contested frame in the visual representation of climate change to explore the cultural meaning-making of the climate through visual news discourse. O'Neill finds that the distancing frame prevalent in the first half of the decade - depicted by polar landscapes - gives way to the contested visual framing of climate change in 2005, accompanied by an increase in protest imagery, cartoons and visual synecdoches, such as smokestacks and wind turbines. These findings shed important light on the cultural meaning-making of climate change at the level of everyday news discourse across time, and the kinds of climate engagements they invite or deny.

Shifting the focus to the communication practices of natural and social science climate scholars, Maxwell Boykoff and David Oonk (2020) explore the opportunities and challenges for climate advocacy beyond professional expectations and disciplinary boundaries. Through online surveys and interviews, US climate scholars were asked about their everyday climate advocacy work beyond their professional commitments, defined here by evidence-based climate science rather than particular policy outcomes. Concerned with exploring the engagement - or science-action-gap, Boykoff and Oonk found that profession (natural versus social scientist), age and gender affected the propensity for climate advocacy by the academic climate community, with social scientists, younger scholars and women more likely to engage in climate advocacy practices. These findings raise important questions on how to better facilitate climate advocacy work for public understanding and engagement, but they also go directly to the crucial role of identity politics in facilitating (or not) engagements with climate science, engagement and action.

The next two papers focus more specifically upon culture as a contested site of climate knowledge and practice by examining the differential constructions and experiences of identity and subjectivity in specific locales and social contexts. Allison Ford and Kari Marie Norgaard

$\overline{3 \text { https://www.academia.edu/44302 }} 947 /$ An_address_to_the_corporales_of_the_Republic_of_Sunlight 
(2020) explore how environmental subjectivities in two different communities in the USA, the Karuk Tribe in California and urban homesteaders, are shaped by cultural values and power relations. Through the intersections of gender and race, Ford and Norgaard explore how each community differentially challenges unsustainable political-economic structures: the urban homesteaders through self-sufficiency and small-scale sustainable living and the Karuk through responsibility to the natural world that acknowledges climate change as the ongoing effect of colonial practices. However, whilst both communities are shaped by concerns for climate change, the urban homesteaders fail to question - and thus reinforce - the colonialist economic-political structures that create climate change. These findings shed important light on the urgent need for intersectional analyses of everyday climate cultures.

Nick Nash, Lorraine Whitmarsh, Stuart Capstick, Valdiney Gouveia, Rafaella De Carvalho Rodrigues Araújo, Monika dos Santos, Romeo Palakatsela, Yubei Lui, Marie K. Harder and Xiao Wang (2020) turn their attention to the role of culture in citizens' understandings of climate change in three culturally diverse emerging economies: Brazil, South Africa and China. Through semi-structured interviews that used a narrative approach to contextualise climate change as part of people's lifestyle narratives, Nash et al. found that people did not spontaneously talk about climate change when asked about environmental issues in their dayto-day lives. Instead, participants talked about issues affecting their local landscape, like water pollution and illegal logging, whilst also situating the local context, and their everyday practices, as inhibiting their capacity to affect change at a political level. The findings call for the need to reconfigure communicative climate practices at the local level in ways that more carefully link to the everyday and situated cultural experiences of people.

The next two papers turn their critical attention to the relationship between users and sociomaterial practices in the socio-technical creation of low carbon economies and societies. David M. Evans, Alison L. Browne, and Ilse Gortemaker (2020) explore the concept of userled environmental leapfrogging as a potential for achieving sustainable patterns of water use in the Global South. The authors consider mobile (cell) phones as an exemplary form of leapfrogging (over landline telephony) given their fit with existing cultural patterns of technological use and acceptance. Evans et al. speculate about the possibility of applying this knowledge of the socio-cultural appropriation of (mobile) technologies to the use of technologies for fostering sustainable household water consumption in the Global South. Their speculations acknowledge how existing socio-cultural practices shape technological use and identify the potential for more radical approaches to environmental leapfrogging beyond the private ownership and use model of the Minority World.

Kersty Hobson (2020) explores how the circular economy (CE) - which moves away from linear production-consumption-disposal systems - interacts with everyday habits and norms. Through interviews with activists and practitioners in the UK and Netherlands, Hobson reflects upon the move towards everyday material relations as one of care and stewardship rather than of use and disposal, and the challenges that the CE poses when situated at the everyday level. Her findings shed much needed light on how the CE needs to be understood in relation to the socio-material practices of the everyday in order for it to achieve the large-scale transformation of socio-industrial practices it promises.

The final two papers turn their attention to the problematic role of corporations in everyday carbon economies and their promotion of a biopolitics of climate capitalism in efforts to mitigate the causes and impacts of climate change. Julie Doyle, Nathan Farrell and Michael K. Goodman (2020) examine the sustainability model of Unilever as indicative of a pivotal moment in the contemporary climate politics of the corporate sector. Through a multimodal 
discourse analysis of Unilever's Sustainable Living Plan, and Project Sunlight campaign, Doyle et al. find that Unilever co-opt the affective and emotional registers of everyday life and human relations to promote climate care as an act of individualised branded consumption. These acts of climate care are invoked through normative discourses of gender and family as a form of biopolitics which situates consumption as a form of responsibilised climate care within climate capitalism. Doyle et al. call for more novel social imaginaries tied to alternative political economies that work for more equitable social change.

Jim Ormond (2020) explores the technological fixes to sustainable food production offered by corporations through the geo-engineered super low carbon cow. Focusing upon greater production efficiencies in meat and dairy production as a means of reducing greenhouse gas emissions, the super low carbon cow_ - geoengineered to produce less methane and more milk or beef for less carbon - becomes responsibilised as an everyday climate actor involved in the mitigation of climate change. In the technologisation of meat and dairy carbon reduction, businesses are (re)positioned from being part of the problem (e.g. a significant source of GHG emissions) to an accepted and 'necessary' part of the solution. Ormond argues that in positioning the cow as both hero and villain of climate change, more structural changes to unsustainable food systems are left unaddressed.

To conclude, we began this introduction by reflecting upon the temporary reduction in global carbon emissions as a result of abrupt changes to daily practices and social systems brought about by COVID-19. Through these impacts, the global pandemic revealed how everyday social and cultural practices are intimately shaped by and intersect with broader socio-economic systems that are inequitable, unjust and unsustainable. In addition, the pandemic has revealed both the urgent need and possibilities for achieving more equitable and sustainable ways of living at the daily and societal level, and the very real challenges that this poses as economies - and the consumer practices they depend upon-quickly return to 'business as usual'. The papers in this Special Issue foreground the need for a sustained and critical interdisciplinary focus upon the role of everyday spaces and cultural practices in the politics of climate change that includes a focus upon the intersections between identities, practices and systems, the relationships of which have been moved front and centre by COVID-19 and its lasting impacts. Individually and collectively, the papers develop new interdisciplinary insights into the ways that the everyday spaces of climate culture, its practices and associated communication regimes are critical to the mitigation and adaptation of societies in the Anthropocene. Just as importantly, however, they situate social science and the humanities at the core of interdisciplinary approaches to the building of societal solutions to climatic change in a post-COVID world, where a focus upon everyday cultures and social practices - as sites of inequality, contestation and change - are crucial to the development of more equitable and sustainable societies.

Acknowledgements This Special Issue arose out of a workshop held at the University of Reading in 2016 entitled 'Practicing Everyday Climate Cultures' that was generously supported by the following funders and individuals at Reading: the Walker Institute (Ros Cornforth); the Global Development Research Division (Rosa Freedman); the Climate, Culture and Society Research Cluster (Alex Arnall and Hilary Geoghegan); the Human Geography Research Cluster (Hilary Geoghegan); The Reading Centre for Climate and Justice (Catriona McKinnon); and the Prosperity and Resilience Research Theme (Dominik Zaum). Additional funding support came from the Media, Communication and Cultural Studies Association (MeCCSA) and the Centre for the Study of Journalism, Culture and Community, Bournemouth University. We wish to thank all of the authors in the Special Issue for their hard work and patience in producing the excellent work here, but also the additional workshop participants of Alexandra Sexton, James Painter, Alex Arnall, Lydia Messling, Alison Anderson, Jo Hamilton, Melanie Rohse, Lucy Veale, Jo Littler and Martin Mahony. A special note of gratitude goes to Sabine 
Mayeux for her invaluable work on and support of the workshop. Many thanks to Alex Sexton, David Evans, Dave McLaughlin and Max Boykoff for reading earlier versions of our editorial introduction to the Issue. Finally we wish to thank Max Boykoff, Mike Mastrandrea, Helen Poulos (Managing Editor) and Lhiric Agoyaoy at Climatic Change for entertaining this set of papers in the journal and for shepherding us from proposal to publication.

\section{References}

Boykoff M (2011) Who speaks for the climate? Making sense of media reporting on climate change. Cambridge University Press, Cambridge

CarbonBrief (2020) Analysis: coronavirus set to cause largest ever annual fall in CO2 emissions. https://www. carbonbrief.org/analysis-coronavirus-set-to-cause-largest-ever-annual-fall-in-co2-emissions Accessed 24 Jul, 2020

de Certeau M (1974) The practice of everyday life. University of California Press, Berkeley

Doyle J (2011) Mediating climate change. Ashgate, Abingdon

Doyle J, Farrell N, Goodman M (2017) Celebrities and climate change: history, politics and the promise of emotional witness. In: Nisbet M (ed) The Oxford encyclopedia of climate change communication. OUP, Oxford

Evans DM (2018) Rethinking material cultures of sustainability: commodity consumption, cultural biographies and following the thing. Trans Inst Br Geogr 43(1):110-121. https://doi.org/10.1111/tran.12206

Evans DM (2019) What is consumption, where has it been going, and does it still matter? Sociological Review 67(3):499-517. https://doi.org/10.1177/0038026118764028

Evans DM (2020) After practice? Material Semiotic Approaches to Consumption and Economy Cultural Sociology, 1-17. https://doi.org/10.1177/1749975520923521

Hall, 2019

Hobson K (2013) On the making of the environmental citizen. Environmental Politics 22(1):56-72. https://doi. org/10.1080/09644016.2013.755388

Hulme M (2016) Weathered: cultures of climate. SAGE Publications, London

IPCC (2014) Climate change 2014: mitigation of climate change. Contribution of working group III to the fifth assessment report of the Intergovernmental Panel on Climate Change. Cambridge University Press, Cambridge

Le Quéré C, Jackson RB, Jones MW, Smith AJP, Abernethy S, Andrew RM et al (2020) Temporary reduction in daily global CO2 emissions during the COVID-19 forced confinement. Nat Clim Chang 10(July):647-654. https://doi.org/10.1038/s41558-020-0797-x

Lefebvre H (2014) The critique of everyday life. Verso, London

Moser S (2016) Reflections on climate change communication research and practice in the second decade of the 21st century: what more is there to say? WIREs Climate Change 7(3):345-369

Munshi D, Kurian P, Cretney R, Morrison SL, Kathlene L (2020) Centering culture in public engagement on climate change. Environmental communication, (May). https://doi.org/10.1080/17524032.2020.1746680

NOAA (2020) 'Rise of carbon dioxide unabated', NOAA Research News, 4 June 2020. https://research.noaa. gov/article/ArtMID/587/ArticleID/2636/Rise-of-carbon-dioxide-unabated accessed 22 Jul 2020

Norgaard KM (2011) Living in denial: climate change, emotions, and everyday life. MIT Press, Cambridge

Shove E (2010) Beyond the ABC: climate change policy and theories of social change. Environ Plan A 42:12731285

Sullivan R (2020) The geography of the everyday. University of Georgia Press, Athens

United Nations (2020a) Climate change and Covid-19: UN urges nations to 'recover better'. https://www.un. org/en/un-coronavirus-communications-team/un-urges-countries-'build-back-better' Accessed 24 Jul, 2020

United Nations (2020b) The Sustainable Development Goals. https://sdgs.un.org/ Accessed 15 Jul, 2020

Vaughan, A (2020) UK citizens' assembly shows big support for green covid-19 recovery. New Scientist https:/www.newscientist.com/article/2246693-uk-citizens-assembly-shows-big-support-for-green-covid-19recovery/ Accessed 24 Jul, 2020

Publisher's note Springer Nature remains neutral with regard to jurisdictional claims in published maps and institutional affiliations. 